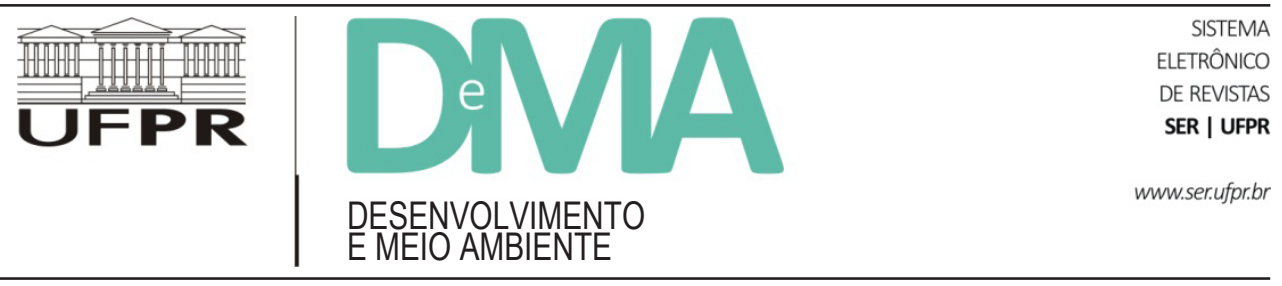

\title{
Aproveitamento do resíduo madeireiro na produção de energia termoelétrica no município de Marcelândia-MT
}

\section{Utilization of Timber Residue on Thermoelectric Energy Production in the City of Marcelândia-MT}

\author{
Udimara Erica Mattei PREILIPPER ${ }^{1 *}$, Wylmor Constantino Tives DALFOVO ${ }^{2}$, Irene Domenes ZAPPAROLI ${ }^{1}$, \\ Lucas Alves MAROUBO ${ }^{1}$, Eriton Luiz MAINARDES ${ }^{3}$ \\ ${ }^{1}$ Programa de Pós-Graduação em Bioenergia, Universidade Estadual de Londrina (UEL), Londrina, PR, Brasil. \\ ${ }^{2}$ Universidade do Estado de Mato Grosso (UNEMAT), Sinop, MT, Brasil. \\ ${ }^{3}$ Programa de Pós-Graduação em Bioenergia, Universidade Estadual de Ponta Grossa (UEPG), Ponta Grossa, PR, Brasil. \\ *E-mail de contato: udimara_89@hotmail.com
}

Artigo recebido em 10 de fevereiro de 2015, versão final aceita em 25 de fevereiro de 2016.

RESUMO: A expansão das atividades humanas na busca de desenvolvimento provoca o aumento da geração de resíduos que, na maioria dos casos, podem ser reaproveitados como insumos de outras atividades econômicas, tornando-as mais sustentáveis. Neste sentido, a pesquisa teve como objetivo analisar as condições ambientais e econômicas que favorecem a produção de energia elétrica a partir do aproveitamento do resíduo madeireiro gerado no município de Marcelândia-MT. Para tanto, foram quantificados os estoques de resíduos existentes neste município a partir de dados fornecidos pela Secretaria de Estado do Meio Ambiente. Em seguida, pelo método estatístico, estimou-se o tempo de extração da área total coberta por vegetação no município. Por fim, os custos e as receitas foram confrontados com a finalidade de demonstrar a rentabilidade da implantação de uma usina termoelétrica. Constatou-se que, em Marcelândia-MT, os resíduos madeireiros gerados entre maio de 2007 e junho de 2012 somam $8.914 .743,13 \mathrm{~m}^{3}$. Neste município, existem 18 manejos florestais, correspondentes a $15.935 .080,97 \mathrm{~m}^{3}$, com potencial de exploração manejada por, pelo menos, 189 anos. Considerando, neste cenário, o aproveitamento médio do volume total de tora (58,54\%), ter-se-ia uma geração total de 6.606.684,57 $\mathrm{m}^{3}$ de resíduos madeireiros, quantidade suficiente para sustentar uma usina termoelétrica por aproximadamente 43 anos, isso sem considerar os resíduos gerados na continuidade da produção madeireira e aqueles gerados por floresta, que seriam suficientes para abastecer uma usina pelo período de 32 anos. O aproveitamento dos resíduos madeireiros gerados em Marcelândia-MT como insumo da usina termoelétrica apresenta-se como uma proposta viável, com taxa interna de retorno próxima à taxa mínima de atratividade esperada, valor presente líquido positivo e retorno do investimento a partir do sexto ano, com lucro de $\mathrm{R} \$ 13.240 .654,00$. Desta forma, a demanda de energia do município $(1.382 .268 \mathrm{kWh})$ poderia ser suprida pela usina termoelétrica e o excedente de energia gerado poderia ser comercializado.

Palavras-chave: resíduo madeireiro; energia renovável; Marcelândia-MT. 
ABSTRACT The expansion of human activities on the quest for development causes an increase in generation of waste which can be reused, in most cases, as inputs to other economic activities, making them more sustainable. In this sense, the research aimed to analyze the environmental and economical conditions that favor the production of electricity from the use of wood waste generated in the municipality of Marcelândia-MT. For that, the existing waste stocks in this county were quantified from data provided by the Ministry of Environment. Then, by the statistical method, the time of extraction of the total area covered by vegetation in the city was estimated. Finally, the costs and revenues were analyzed to demonstrate the profitability of the establishment of a thermal power plant. It was found that in Marcelândia-MT, the wood waste generated between May 2007 and June 2012 add up to $8,914,743.13 \mathrm{~m}^{3}$. In this municipality, there are 18 forest managements, amounting to $15,935,080 \mathrm{~m}^{3}$, with the potential to be exploited in a managed way for at least 189 years. Considering in this scenario, the average utilization of total $\log (58.54 \%)$ would have a complete generation of $6,606,684.57$ $\mathrm{m}^{3}$ of wood waste, enough to sustain a thermal power plant for about 43 years, this without considering the waste generated in the continuity of timber production and those generated by forest, which would be enough to supply a plant for a period of 32 years. The use of wood waste generated in Marcelândia-MT as input of the power plant is presented as a viable proposal, with internal rate of return close to the minimum expected rate of attractiveness, positive net present value and return on investment from the sixth year, with income of R $\$$ $13,240,654.00$. In this way, the city's energy demand $(1,382,268 \mathrm{kWh})$ could be supplied by the power plant and the generated surplus power could be marketed.

Keywords: waste timber; renewable energy; Marcelândia-MT.

\section{Introdução}

Existe, no Brasil, uma necessidade em manter a matriz energética diversificada, com o intuito de garantir com segurança o fornecimento de energia a diversos setores (industrial, residencial, comercial, transportes, entre outros), de modo que os sustentem, em termos de quantidade e disponibilidade de energia. Neste sentido, as indústrias termoelétricas têm aumentado sua participação na geração de energia elétrica (aumento de 4,3\% entre 2013 e 2014), ganhando espaço das fontes de energia hidráulicas (queda de 4,5\% entre 2013 e 2014 na geração hidrelétrica) (Brasil, 2015).

Entre os insumos usados nas indústrias termoelétricas, a biomassa florestal tem ganhado destaque, por apresentar condições de exploração a partir da utilização de resíduos oriundos da colheita e da transformação da madeira (Teixeira, 2009), como, por exemplo, refilos, serragem, cascas, maravalha e cavaco. Se estes resíduos, quando não utilizados, são dispostos de forma inadequada, podem provocar uma série de impactos sobre o meio físico, que envolve o solo, as águas superficiais e subterrâneas e o ar, e também sobre os meios biológico e socioeconômico.

No Brasil, por falta de alternativas de destinação imediata, grandes quantidades desses resíduos são simplesmente empilhadas, encontrando-se em diversos estágios de decomposição. Muitas vezes, estes resíduos são queimados a céu aberto ou sofrem combustão espontânea, emanando particulados finos para a atmosfera (Farra, 2004, p. 8).

Rosalino \& Dalfovo (2011) destacam o Estado de Mato Grosso como um dos principais estados brasileiros produtores de madeira em toras nativas: com 1.684 indústrias, consome cerca de 3,6 milhões de metros cúbicos de toras nativas ao ano. No Mato Grosso, evidencia-se o município de Marcelândia, pela grande quantidade de empresas madeireiras ativas, que geraram, no ano de 2010 , cerca de 410 mil $\mathrm{m}^{3}$ de resíduos provenientes da transformação de madeira, os quais não possuem destino definido, ficando expostos a céu aberto. 


\section{Desenvolvimento e meio ambiente}

A modernização do sistema econômico e a expansão das atividades humanas na busca do bem-estar influenciam de forma significativa no aumento da geração de resíduos, podendo causar poluição. Andrade (2008, p. 10) considera a poluição como uma "externalidade negativa", evidenciando o meio ambiente como um bem público, na função de receptor de rejeitos.

Para Amazonas (2012), as externalidades são causadas pelas inúmeras condições de ineficiência de mercado, as chamadas falhas de mercado, devido ao caráter de bem público dos recursos naturais, ou seja, não exclusividade de seu uso. Assim as empresas, por exemplo, tornam-se poluidoras devido ao uso dos recursos - sejam eles solo, minerais, água, recursos florestais madeireiros e não madeireiros - em quantidade superior àquela considerada socialmente "ótima". E os cidadãos, atingidos pelo efeito da poluição, defendem seus direitos de terem estes recursos disponíveis em quantidade e qualidade socialmente aceitáveis.

Portanto, para haver correção dessa falha, Andrade (2008, p. 11) ressalta que é necessária a criação de mecanismos institucionais de controle, ou seja, taxação e licença de poluição, "capazes de promover a internalização das externalidades no cálculo econômico dos agentes", fazendo com que o nível socialmente "ótimo" de poluição venha a existir.

No caso dos recursos madeireiros, Teixeira \& César (2006) destacam que as indústrias aproveitam em torno de $30 \%$ a $60 \%$ de todas as árvores que são processadas, existindo uma variação de empresa para empresa. Desta forma, verifica-se que o processo de transformação da madeira gera uma grande quantidade de resíduos, sendo que, quando não servem para o comércio regular, muitas vezes são descartados irregularmente ou queimados, causando efeitos prejudiciais ao meio ambiente.

Neste contexto, os resíduos de biomassa florestal podem ser identificados como uma "externalidade negativa" e uma das formas de internalizá-los seria inserir estes resíduos como matéria-prima para produção de energia a partir de usinas termoelétricas, atendendo, em consequência, a necessidade de diversificação da matriz energética no Brasil, além de possibilitar a geração de empregos e renda e de instigar o desenvolvimento local.

\section{Biomassa como fonte de energia}

O interesse por fontes energéticas como a biomassa ganhou espaço pelo fato de esta fonte ser considerada limpa e renovável. Em outras palavras, trata-se de uma alternativa correta dos pontos de vista ambiental e econômico, por gerar energia advinda de insumos produzidos pela natureza ou decorrente de processos que utilizam recursos naturais renováveis (Preto \& Mortoza, 2010, p. 7).

Os resíduos madeireiros compõem parte importante da quantidade de biomassa disponível para geração de eletricidade em alguns países e reúnem condições favoráveis para substituir os combustíveis fósseis como fonte de energia. Além de serem geradas grandes quantidades de resíduos de madeira durante a colheita e a ação industrial, a "madeira e seus resíduos são muito utilizados para gerar energia devido à sua capacidade calorífica" (Teixeira, 2009, p. 20).

No Brasil, do total de energia elétrica ofertada internamente, $7,3 \%$ é proveniente da biomassa, o que inclui lenha, bagaço de cana, lixívia e outros resíduos, representando a terceira maior fonte energética do país (Brasil, 2015). 
Segundo dados da Agência Nacional de Energia Elétrica (ANEEL, 2012) ${ }^{1}$, até junho de 2012 o Brasil apresentava 436 usinas termoelétricas movidas a biomassa, o que corresponde a um total de 9.289.937 kW (quilowatts) instalados. Do total destas usinas relacionadas, 14 eram abastecidas por licor negro (resíduo da celulose), com capacidade de (1.245.198 kW); 43 por madeira $(376.535 \mathrm{~kW})$; 19 por biogás $(77.308 \mathrm{~kW})$; oito por casca de arroz (32.608 kW) e 352 por bagaço de cana (7.558.288 $\mathrm{kW})$. Tais empreendimentos são praticamente todos de pequeno porte, o que facilita a instalação nas proximidades dos centros de consumo e de suprimento.

Em países como a Europa, metade do consumo de energia renovável vem do uso da madeira, seja na forma de lenha, serragem ou granulado. $\mathrm{Na}$ Alemanha, mesmo com o incentivo direcionado para as energias eólica e solar, que são subsidiadas pelo governo, $38 \%$ do consumo de combustíveis não fósseis vem da madeira. E em países como a Polônia e Finlândia, a madeira corresponde a $80 \%$ da demanda por energias renováveis (REMADE, 2013).

No Brasil, os resíduos florestais usados para geração de energia ainda representam um pequeno percentual, quando comparado com outros tipos de biomassa. Cortez, Lora \& Gómez (2008, p. 18) enfatizam que "essa fonte energética está encontrando mercado, em consequência do desenvolvimento tecnológico e dos baixos custos que representam sua utilização eficiente".

\section{Panorama do setor florestal brasileiro}

AAssociação Brasileira de Produtores de Florestas Plantadas (ABRAF, 2011, p. 96) ressalta que o setor florestal brasileiro é considerado estratégico, principalmente no que diz respeito ao fornecimento de matéria-prima para o desenvolvimento da indústria nacional de base florestal.

Juvenal \& Mattos (2002, p. 5) ressaltam que o setor de base florestal e de extração de madeira apresenta uma dinâmica específica que é "determinada pela oferta de madeira e pela produtividade das florestas". Ou seja, essa dinâmica depende do ritmo dos reflorestamentos e da produtividade das florestas nacionais (nativas e plantadas), além do crescimento do consumo dos diversos produtos à base de madeira (Vital, 2009, p. 79).

Segundo o Instituto Mato-Grossense de Economia Agropecuária (IMEA, 2012), o setor de base florestal representa a quarta economia do Estado de Mato Grosso, com um Produto Interno Bruto (PIB) de R\$ 57.294.192, que representa 15\% do PIB industrial do Estado.

Segundo Santos (2011, p. 58), “em 2010 estavam cadastrados 4.252 empreendimentos madeireiros na Secretaria de Estado do Meio Ambiente (SEMA) do Estado de Mato Grosso".

\section{Métodos}

Para o processo de levantamento dos dados dos estoques de biomassa madeireira, utilizou-se o banco de dados da Secretaria de Estado do Meio Ambiente (SEMA), descrevendo a produção madeireira indústria por indústria, comparando os resíduos gerados dentro do processo de classificação de origem e de destino estabelecido pela SEMA, pelo aproveitamento total do volume de tora consumida por todas as indústrias madeireiras do município de Marcelândia-MT, possibilitando, assim, evidenciar o percentual de aproveitamento total da tora.

Já para estimar o tempo de consumo da área coberta por floresta referente ao município de

\footnotetext{
1 Retirado do Banco de Informações de Geração da ANEEL.
} 
Marcelândia-MT foi necessário identificar o número total de manejos florestais existentes naquela localidade para que, assim, fosse realizada a técnica estatística do processo de amostragem aleatória simples, que inclui métodos estatísticos como: estimativas, média, variância, desvio padrão, erro padrão, erro de amostragem, intervalo de confiança, dentre outras grandezas da estatística.

Neste sentido, localizou-se, por meio do banco de dados da empresa de Serviços Florestais e Assessoria Empresarial (Bio Versátil), um total de 18 manejos de floresta nativa. Então, realizou-se a divisão da área dos manejos e da área coberta por floresta em parcelas de 100 hectares para a quantificação do total de parcelas existentes na área coberta por floresta. Com estes dados, fez-se uso do método já comentado para quantificar o tempo total estimado de consumo da área coberta por floresta, levando-se em consideração, ceteris paribus, a quantidade $\left(\mathrm{m}^{3}\right)$ autorizada pela SEMA a ser explorada pelos 18 manejos florestais, durante o período de esgotamento da área florestal.

Outro ponto a ser destacado foi o estudo da análise econômico-financeira do projeto, que determinou a rentabilidade ou não do empreendimento, empregando técnicas de análise de viabilidade como: Fluxo de Caixa, Valor Presente Líquido (VPL), Taxa Interna de Retorno (TIR) e Tempo de Retorno do Investimento (Payback), com o intuito de demonstrar a viabilidade da instalação da usina termoelétrica para a geração de energia elétrica através do consumo do resíduo madeireiro produtivo no município de pesquisado.

Para demonstração da viabilidade da usina, fez-se necessária a conversão da medida de $\mathrm{m}^{3}$ para kg, para melhor compreensão do montante de resíduo madeireiro a ser consumido pela caldeira.

Deste modo, realizou-se o cálculo de determinação da densidade do pó de serra, onde, com o auxílio de uma espátula, se colocou o pó de serra (previamente seco) em um recipiente com volume interno exato de um litro. Em seguida, com o auxílio de uma balança de precisão, determinou-se o peso do pó contido no recipiente, tarando previamente a balança. Para obter maior precisão, efetuou-se uma sequência de 10 medidas, conforme demonstrado na Tabela 1, a partir das quais se fez uma média, encontrando a densidade do pó de serra, que é de $0,276 \mathrm{~kg} / \mathrm{litro}$ ou $276 \mathrm{~kg} / \mathrm{m}^{3}$.

TABELA 1 - Medida das 10 amostras de pó de serra coletadas no município de Marcelândia-MT.

\begin{tabular}{cc}
\hline Amostra & Densidade (kg/l) \\
\hline 1 & 0,281 \\
2 & 0,271 \\
3 & 0,275 \\
4 & 0,277 \\
5 & 0,276 \\
6 & 0,278 \\
7 & 0,274 \\
8 & 0,279 \\
9 & 0,273 \\
10 & 0,276 \\
\hline
\end{tabular}

FONTE: Elaboração própria.

Após, realizadas todas estas etapas do processo, foi necessário quantificar o consumo de resíduo de madeira da usina termoelétrica, considerando o poder calorífico inferior (PCI) da serragem seca (20\% de água), que é de $3.500 \mathrm{kcal} / \mathrm{kg}$. Segundo dados de Benecke (2012), uma caldeira que gera o equivalente a 5 MWh com uma eficiência de $83 \%$ consome 6,5 toneladas de resíduos.

\section{Apresentação e análise dos resultados}

\subsection{Breve perfil econômico do setor madeireiro}

O município de Marcelândia localiza-se na região norte do Estado de Mato Grosso, mais 
precisamente na microrregião de Sinop. Possui uma extensão territorial de $12.294 \mathrm{~km}^{2}$, onde faz fronteira com os municípios de Peixoto de Azevedo, São Félix do Araguaia, São José do Xingu, Feliz Natal, União do Sul e Nova Santa Helena.

Conforme dados da Prefeitura Municipal de Marcelândia (2012), o município foi fundado em 1980, tendo início a partir de um projeto de colonização sob responsabilidade da Colonizadora Maiká. Com o objetivo de trabalhar com pecuária extensiva, desenvolveram inicialmente a atividade de desmatamento, encontrando as melhores oportunidades no setor florestal extrativista, criando possibilidade de instalação para as serrarias no município.

As dificuldades da época não impediram a comercialização da madeira beneficiada para o Estado de São Paulo no ano de 1980, dando impulso à colonização e ao desenvolvimento da cidade (Oliveira, 2011). Assim, além do beneficiamento da madeira no município, os madeireiros encontraram condições favoráveis para o fornecimento de matéria-prima para a indústria madeireira em outras cidades, como Sinop (PNUD, 2005).

Oliveira (2011) destaca que em 1986, no auge da indústria madeireira, a cidade contava com cerca de 200 indústrias, produzindo diariamente de 1.200 a $1.300 \mathrm{~m}^{3}$ de madeira. Porém, para efeito de análise, convencionou-se demonstrar os dados da produção de toras por valor produzido no setor extrativista a partir do ano de 2002, conforme a Figura 1.

Percebe-se que o valor de produção extrativista de madeira em tora analisada no município de Marcelândia-MT a partir de 2002, demonstrado na Figura 1, apresentou uma linha de tendência de queda dos preços que seguiu até o ano de 2008. Segundo Ventura (2012), este fato foi motivado pela redução da produção e pela valorização do real frente ao dólar no mesmo período.

Desta forma, a redução da produção pode ser explicada também pelas várias operações realizadas por órgãos fiscalizadores e ambientais, em específico, a Operação Curupira, realizada em 2005, deflagrada pela Polícia Federal, que teve como objetivo coibir a extração e o transporte ilegal de madeira (Portal Mato Grosso, 2012).

A Figura 1 demonstra ainda o expressivo aumento no valor produzido de madeira extrativista para o ano de 2009 e Ventura (2012, p. 51) explica que esse crescimento está relacionado à "demanda de madeira empregada pela construção civil fomentada pelo Plano de Aceleração do Crescimento (PAC) e o programa 'Minha Casa, Minha Vida', desenvolvido pelo Governo Federal".

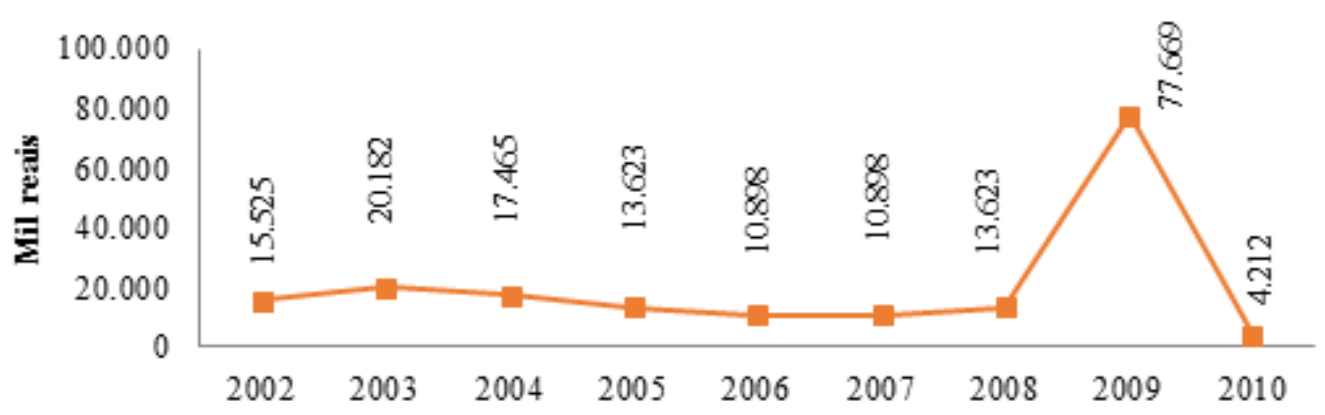

FIGURA 1 - Valor da produção extrativista de madeira em tora no período de 2002 a 2010 no Município de Marcelândia-MT. FONTE: IBGE (2012). 
Porém, no ano de 2010 houve uma redução no valor da produção madeireira de $94,58 \%$ em relação a 2009, em virtude da baixa produção extrativista de toras que ocorreu pela forte atuação de órgãos fiscalizadores e ambientais (IBGE, 2010).

São comuns flutuações expressivas na atividade madeireira, devido à grande quantidade de indicadores, como a demanda industrial, o preço e a atuação de órgãos de controle ambiental e fiscal, que influenciam no valor gerado pelo setor (IBGE, 2010).

Portanto, o município de Marcelândia-MT atingiu seu grau de importância no setor madeireiro devido a sua grande participação na produção de madeira extrativista, pois, dada a importância que o setor representa para o município, entende-se que, para manter a demanda de tal atividade, são necessárias alternativas sustentáveis, como a exploração de florestas nativas através dos manejos.
Os planos de manejo de florestas nativas são considerados como um instrumento de gestão quanto aos recursos florestais e são vistos pelas indústrias do setor madeireiro como uma garantia do estoque de matéria-prima e de sustentabilidade para o setor.

\subsection{Manejos florestais: perspectivas atuais e futuras}

O setor florestal apresenta grande importância econômica, gerando emprego e renda à população. Assim, para suprir a demanda do setor não é necessário aumentar indiscriminadamente e desordenadamente a extração da madeira, mas tomar medidas que minimizem os efeitos sobre a exploração das florestas nativas, conforme a Figura 2.

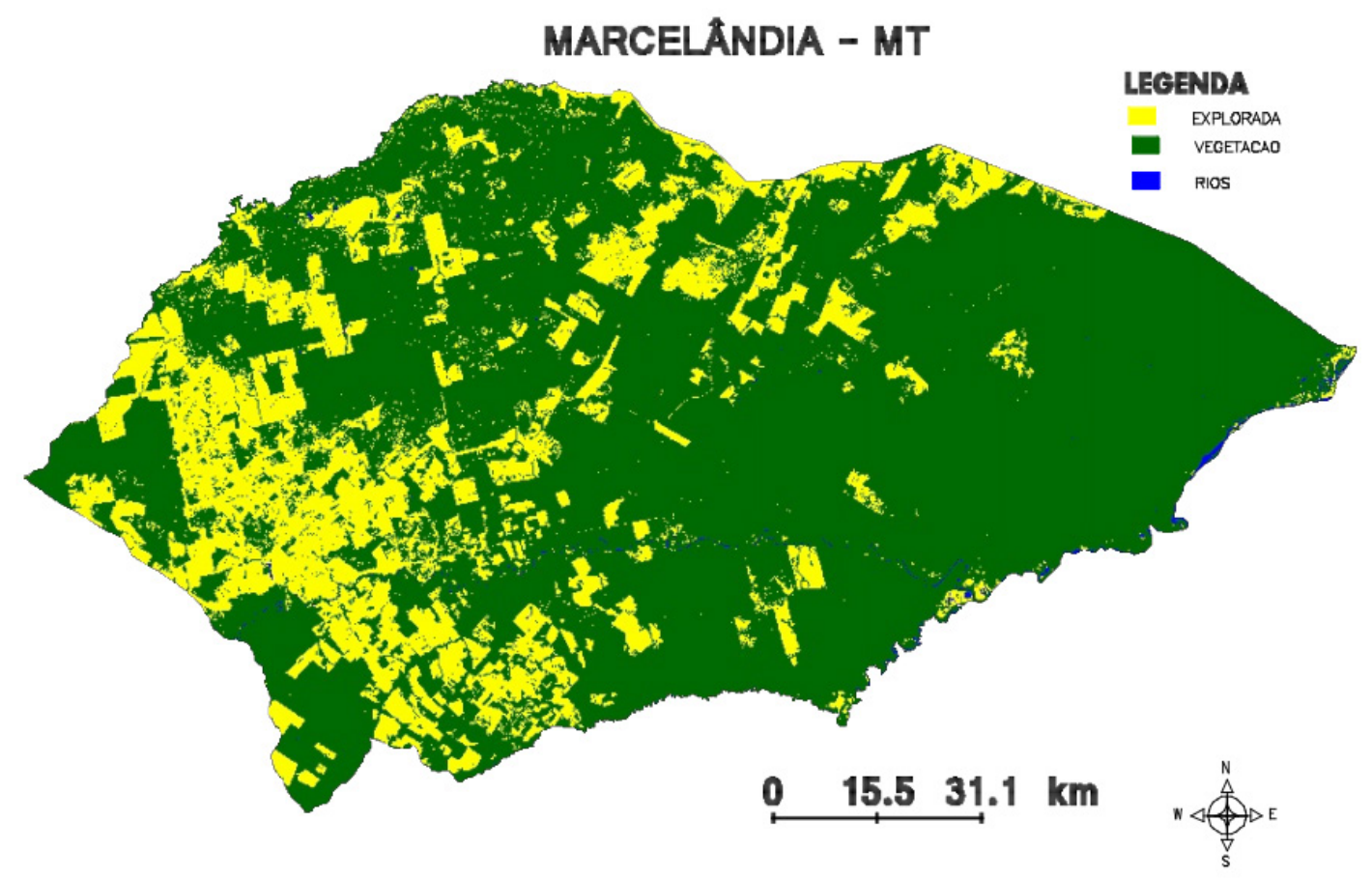

FIGURA 2 - Relação de área coberta por floresta e área desmatada no município de Marcelândia-MT no ano de 2012. FONTE: Bio Versátil (2012). 
Até o ano de 2012, a área explorada apresentava uma extensão equivalente a $2.674,83 \mathrm{~km}^{2}$, ou seja, aproximadamente $27,87 \%$ do total de sua área territorial. Da área restante, $9.597,19 \mathrm{~km}^{2}$ correspondem à cobertura florestal e apenas $36,52 \mathrm{~km}^{2}$ são referentes à área de rios existentes (Figura 2).

Ressalta-se ainda que, na Figura 2, não foram consideradas as Áreas de Preservação Permanente (APP) pelo fato de que não há como identificá-las através dos pixels na imagem. Além disso, do total da área coberta por floresta $(959.719,14 \mathrm{ha})$,
142.647,77 ha são pertencentes à área de reserva indígena.

Na Figura 3, é demonstrada a localização dos manejos existentes dentro do município de Marcelândia-MT. Tais dados apresentam relevância para o setor no município, pois, a partir do número de manejos identificados e da capacidade de exploração da madeira nativa $\left(\mathrm{em} \mathrm{m}^{3} / \mathrm{ha}\right)$, criam-se condições para estimar o consumo desses manejos ao longo dos próximos anos, conforme demonstrado na Tabela 2.

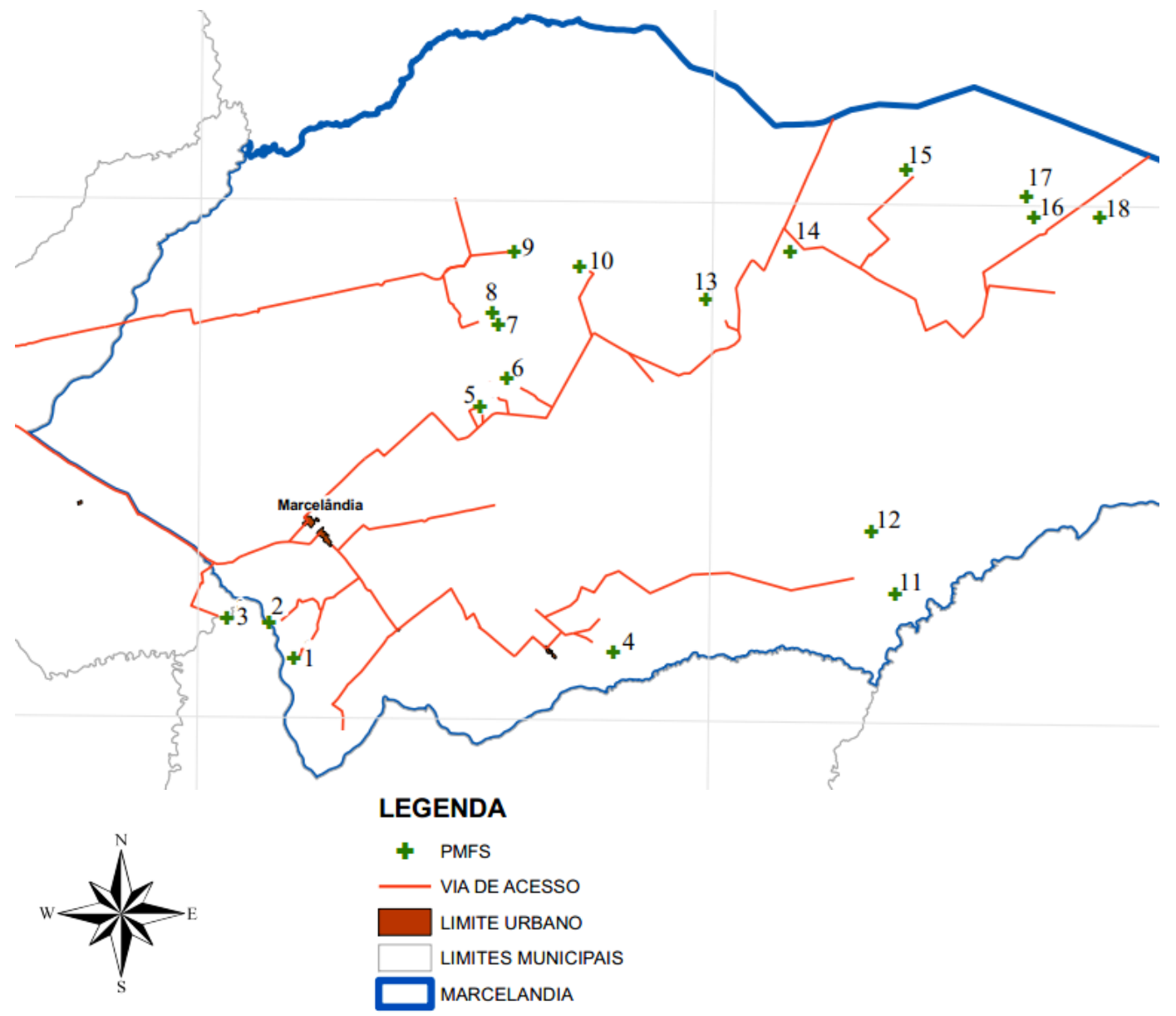

* PMFS: Plano de Manejo Florestal Sustentável.

FIGURA 3 - Mapa de localização do total de manejos florestais no município de Marcelândia-MT.

FONTE: Bio Versátil (2012). 
TABELA 2 - Capacidade de produção dos manejos florestais localizados no município de Marcelândia.

\begin{tabular}{|c|c|c|c|c|c|c|}
\hline $\mathbf{N}^{\mathbf{o}}$ & $\begin{array}{c}{ }^{*} \operatorname{CLCF}\left(\mathbf{m}^{3} / \mathbf{h a}\right) \\
\text { (A) }\end{array}$ & $\begin{array}{c}\text { Volume das } \\
\text { parcelas de } 100 \text { ha }\end{array}$ & $\begin{array}{l}* * \operatorname{AUTEX}(\mathrm{ha}) \\
\text { (B) }\end{array}$ & $\begin{array}{c}{ }^{*} \text { CLCF }\left(\mathbf{m}^{3}\right) \\
(\mathbf{C})=\left(\mathrm{A}^{*} \mathrm{~B}\right)\end{array}$ & Emissão & Validade \\
\hline 1 & 23,98 & $2.398,19$ & 864,01 & $20.720,74$ & 2008 & 2013 \\
\hline 2 & 19,02 & $1.901,90$ & 404,89 & $7.700,62$ & 2009 & 2014 \\
\hline 3 & 30,92 & $3.091,70$ & 429,90 & $13.291,11$ & 2009 & 2014 \\
\hline 4 & 27,56 & $2.755,90$ & 269,78 & $7.435,03$ & 2011 & 2012 \\
\hline 5 & 16,19 & $1.619,50$ & 380,75 & $6.166,24$ & 2011 & 2013 \\
\hline 6 & 23,77 & $2.377,20$ & 911,28 & $21.663,08$ & 2009 & 2010 \\
\hline 7 & 19,02 & $1.902,20$ & 624,92 & $11.887,34$ & 2008 & 2013 \\
\hline 8 & 19,18 & $1.917,70$ & 484,97 & $9.300,33$ & 2011 & 2012 \\
\hline 9 & 16,86 & $1.685,84$ & 925,11 & $15.595,87$ & 2008 & 2013 \\
\hline 10 & 15,62 & $1.562,10$ & $1.073,10$ & $16.762,87$ & 2008 & 2013 \\
\hline 11 & 21,80 & $2.180,30$ & $2.054,31$ & $44.790,07$ & 2008 & 2013 \\
\hline 12 & 20,94 & $2.094,10$ & $1.964,06$ & $41.129,30$ & 2008 & 2013 \\
\hline 13 & 34,25 & $3.425,40$ & 134,61 & $4.611,01$ & 2008 & 2013 \\
\hline 14 & 17,98 & $1.797,64$ & 470,68 & $8.461,17$ & 2008 & 2013 \\
\hline 15 & 22,48 & $2.248,38$ & $1.716,30$ & $38.588,91$ & 2008 & 2013 \\
\hline 16 & 14,95 & $1.495,41$ & 453,41 & $6.780,41$ & 2010 & 2011 \\
\hline 17 & 17,23 & $1.723,20$ & 974,14 & $16.786,36$ & 2008 & 2013 \\
\hline 18 & 37,20 & $3.719,80$ & $1.225,33$ & $45.579,94$ & 2009 & 2010 \\
\hline
\end{tabular}

FONTE: Bio Versátil (2012). Elaboração própria.

* CLCF: Comprovante de Liberação de Crédito Florestal.

**AUTEX: Área com Autorização para Exploração Florestal.

Os rendimentos em $\mathrm{m}^{3} / \mathrm{ha}$ se referem à liberação de crédito florestal por área autorizada dos projetos, apresentando rentabilidades diferentes de manejo para manejo, isso devido à assimetria da floresta, ou seja, concentradas ora em maior, ora em menor quantidade de espécies, justificando a variação de metros cúbicos por hectare em cada manejo.

Quanto à estimativa de tempo máximo e mínimo de consumo do volume total de madeira disponíveis na área total coberta por vegetação (817.071,37 ha) no município de Marcelândia-MT, tem-se os cálculos estatísticos (Tabela 3).

Para os cálculos da Tabela 3, utilizou-se o processo de amostragem aleatória simples, onde se dividiu a área total de vegetação $(817.071,37$ ha) em parcelas de 100 hectares, padronizando a possível exploração de toda a madeira do município de Marcelândia-MT. Para isso, levou-se em consideração o número de autorizações de exploração em $\mathrm{m}^{3}$ liberadas pela SEMA, o período de exploração e a quantidade de manejos, conforme a Tabela 2.

Para chegar ao resultado da estimativa do tempo de exploração na área determinada, multiplicou-se o resultado do intervalo de confiança pelo total do número de parcelas (100 ha). Assim, tem-se o valor estimado em metros cúbicos da madeira existente na área determinada do município, sendo que através deste resultado efetuou-se a divisão pela média de extração de madeira dos 18 manejos autorizados. 
TABELA 3 - Estatística descritiva e estimativa do tempo de consumo do volume total de madeira existente no município de Marcelândia de forma manejada.

\begin{tabular}{|c|c|c|}
\hline & \multicolumn{2}{|c|}{ Resultados } \\
\hline Número de parcelas de 100 ha (P) & \multicolumn{2}{|c|}{$8.170,71$} \\
\hline Número total de amostras (A) & \multicolumn{2}{|c|}{18} \\
\hline População (1 - (A).(P)-1) & \multicolumn{2}{|c|}{0,9978} \\
\hline Média das parcelas (100 ha) & \multicolumn{2}{|c|}{$2.216,47 \mathrm{~m}^{3} /$ parcela } \\
\hline Variância dos volumes & \multicolumn{2}{|c|}{$420.380,51 \mathrm{~m}^{3} /$ parcela } \\
\hline Variância média & \multicolumn{2}{|c|}{$23.303,02 \mathrm{~m}^{3} /$ parcela } \\
\hline Desvio padrão & \multicolumn{2}{|c|}{$648,37 \mathrm{~m}^{3} /$ parcela } \\
\hline Erro padrão da média & \multicolumn{2}{|c|}{152,65} \\
\hline Erro absoluto $5 \%$ & \multicolumn{2}{|c|}{$322,10 \%$} \\
\hline Distribuição t Student & \multicolumn{2}{|c|}{$(2,11)$} \\
\hline Erro absoluto $10 \%$ & \multicolumn{2}{|c|}{$265,62 \%$} \\
\hline Distribuição t Student & \multicolumn{2}{|c|}{$(1,74)$} \\
\hline \multirow[t]{2}{*}{ Coeficiente de variação } & \multicolumn{2}{|c|}{$29 \%$} \\
\hline & Mínimo & Máximo \\
\hline Intervalo de confiança de $5 \%$ & $1.894,37$ & $2.538,57$ \\
\hline Tempo estimado de exploração (ano) & 184 & 246 \\
\hline Intervalo de confiança de $10 \%$ & $1.950,85$ & $2.482,09$ \\
\hline Tempo estimado de exploração (ano) & 189 & 241 \\
\hline
\end{tabular}

FONTE: Elaboração própria.

A partir desta afirmação e considerando os cálculos da Tabela 3, adotaram os intervalos de confiança de $5 \%$ e $10 \%$ para estimar o tempo de exploração da área total de vegetação. Sendo assim, o intervalo de confiança aceito foi o de $10 \%$, pois apresentava o menor erro entre os dois intervalos.

Os cálculos apontaram que, em na condição ceteris paribus, os 18 manejos florestais existentes em Marcelândia-MT têm potencial de ser explorados de forma manejada por, no mínimo, 189 anos, quando se atingiria o esgotamento das florestas nativas deste município, considerando uma exploração média anual de $84.312,59 \mathrm{~m}^{3}$. Considerando tais informações, temos que o valor de extração estimada será de 15.935.080,97 $\mathrm{m}^{3}$.

Sendo assim, constatou-se que a produção madeireira em Marcelândia-MT apresenta condições favoráveis para desenvolver-se sustentavelmente, possuindo matéria-prima suficiente para manter o setor madeireiro ativo por longo tempo e capacidade de manter a exploração manejada da floresta nativa de acordo com as normativas deliberadas pela Secretaria do Meio Ambiente.

\subsection{A atividade madeireira e os estoques de resíduos gerados no período de 2007 a 2012}

De acordo com as pesquisas de campo realizadas no município de Marcelândia-MT, notou-se que o aproveitamento referente ao processo de beneficiamento da madeira possui um percentual baixo, tendo em média para algumas espécies um aproveitamento superior a $60 \%$, como no caso da espécie itaúba, e para outras espécies um aproveitamento abaixo dos 50\%, como nos casos do cedrinho, canelão e cambará.

Neste sentido, mesmo o município sendo atualmente considerado um dos grandes produtores de madeira serrada, evidencia-se uma deficiência quanto ao aproveitamento dos resíduos gerados antes e durante o processo de transformação da madeira.

A Secretaria de Estado e Meio Ambiente (SEMA), por meio da Portaria $n^{\circ} 096 / 2010$, classifica a madeira respectivamente em origem e destino. Portanto, tem-se que a classificação de origem está relacionada à geração de resíduos oriundos antes de qualquer transformação da tora, ou seja, são considerados os resíduos gerados durante a extração, por exemplo, cascas, galhos e ápices, até o primeiro processo de beneficiamento da tora, onde são realizados a retirada das costaneiras e o destopo da mesma, onde se faz a retirada de pontas estragadas ou inúteis do tronco, pranchas ou tábuas, deixando seções do seu tronco ou sua principal parte em formato roliço destinada ao processamento industrial (SEMA, 2010). 
Com relação à classificação de destino, relaciona-se com a geração de resíduos provenientes do processamento industrial da tora, ou seja, são resíduos gerados a partir da fabricação de produtos e subprodutos destinados à comercialização final, conforme exposto na Tabela 4.

Verifica-se uma redução na quantidade de indústrias ligadas ao setor madeireiro no período de maio de 2007 a junho de 2012, entre serrarias, madeireiras e laminadoras, que beneficiam grande parte da madeira extraída no município, sendo esta redução em torno de $40 \%$ neste período.

Sendo assim, a soma total dos resíduos gerados e classificados (origem e destino), entre maio de 2007 e junho de 2012, chega a 8.914.743,13 m³, valor este correspondente a $2.460 .469 .109,10 \mathrm{~kg}$ de pó de serra (considerando a densidade do pó de serra obtida empiricamente - vide Tabela 1).

Entretanto, com relação ao aproveitamento médio das toras de madeira nativa, este gira em torno dos $58,54 \%$ em relação à geração de resíduos analisados durante o processamento classificado como destino.

Ressalta-se ainda que nos anos de 2007 e 2012 os dados sobre o aproveitamento do volume total de toras apresentaram um comportamento de alta em relação à média analisada no período, chegando a 77,25\% em 2007 e 61,22\% em 2012. Salienta-se que, para esses anos, os dados sobre a produção de resíduos madeireiros são parciais, portanto, não foram contabilizados todos os resíduos produzidos durante o ano, motivo pelo qual os percentuais de aproveitamento são mais altos que a média.

TABELA 4 - Classificação dos resíduos de madeira gerados $\left(\mathrm{m}^{3}\right)$ no município de Marcelândia-MT no período de maio/2007 a junho/2012.

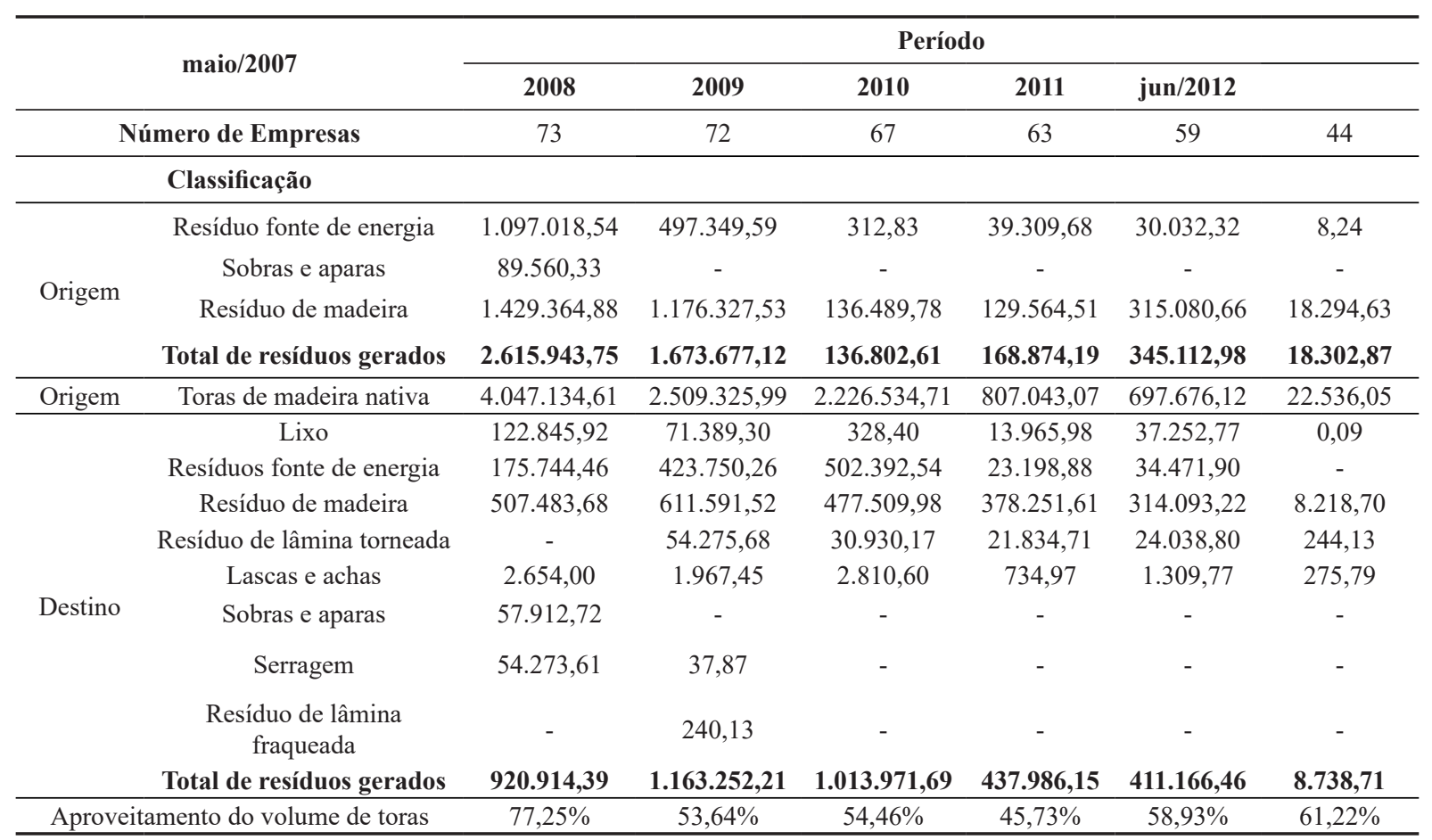

FONTE: SEMA (2012). 
Já para o ano de 2010, o valor do aproveitamento do volume de toras ficou abaixo da média, em torno de 45,73\%. Segundo o Centro de Inteligência em Florestas (Ciflorestas, 2010), tal situação pode ser elucidada pelo incêndio ocorrido em agosto daquele ano, que acabou consumindo parte considerável da produção de madeira serrada, laminada e em tora que estava no pátio das 10 indústrias madeireiras atingidas.

Além desses fatos, o baixo rendimento do volume de tora pode também estar relacionado, na maioria dos casos, ao "atraso tecnológico, máquinas obsoletas", falta de treinamento da mão de obra, dentre outros fatores que influenciam no mau aproveitamento do volume de toras, gerando grandes quantidades de resíduos (Gomes \& Sampaio, 2004).

Portanto, conforme os dados apresentados, destaca-se que o município de Marcelândia-MT apresenta um volume considerável de geração de resíduos madeireiros, os quais ainda não possuem destinação correta, ficando expostos a céu aberto e gerando um problema para as indústrias madeireiras, à medida que ocupam espaço e mão de obra para sua remoção, além de contribuir para poluição do meio ambiente.

Vale ressaltar que os estoques excedentes provenientes da aquisição de produtos madeireiros sem origem comprovada ou qualquer outro motivo que descumpra as normas vigentes estabelecidas pela Secretaria de Estado do Meio Ambiente não são ajustados aos dados publicados (SEMA, 2010).

Portanto, após descrita a média de aproveitamento do volume total de tora $(58,54 \%)$ e com os cálculos realizados para estimar o tempo para a exploração total da área coberta por vegetação no município de Marcelândia-MT, considerando estas variáveis, ter-se-á uma extração estimada de 15.935.080,97 $\mathrm{m}^{3}$ em um período mínimo de 189 anos, partindo do momento atual dos cálculos, ou seja, do ano de 2012, com uma geração total de $6.606 .684,57 \mathrm{~m}^{3}$ de resíduos a serem aproveitados economicamente.

\subsection{Descrição da estrutura física da usina termoelétrica movida a biomassa madeireira}

Após a descrição do volume total de resíduos gerados durante o processo de beneficiamento da madeira (2007 a 2012) e a previsão dos estoques referentes à área total coberta por floresta a ser manejada em Marcelândia-MT, tem-se que a utilização dos resíduos madeireiros oferece capacidade de geração de um valor econômico, neste caso, por exemplo, para fim energético.

Neste sentido, o processo de conversão da biomassa madeireira em energia pode ser realizado de forma simples, por meio da combustão em fornos e caldeiras, ou por meio de formas mais complexas, utilizando elaborados procedimentos industriais, como a gaseificação, a pirólise e a cogeração.

Deste modo, como alternativa para a geração de energia elétrica por meio do consumo de resíduos madeireiros oriundos das indústrias de beneficiamento de madeira, localizados no município de Marcelândia-MT, temos a descrição técnica da caldeira aquatubular ${ }^{2}$ que será usada na usina, de acordo com a Tabela 5 .

Conforme a Tabela 5, são mostrados os dados referentes às condições técnicas de funcionamento da caldeira a vapor, que possui uma eficiência de combustão voltada para combustíveis sólidos, tais como: costaneiras, picado de madeira, mistura

\footnotetext{
2 Segundo Fontenelle (2012, p. 7), nas caldeiras aquatubulares a água que irá ser aquecida passa no interior dos tubos, sendo vaporizada, pois os gases de combustão circulam fora da tubulação. Geralmente usadas na produção igual ou maior que 5 MWh de energia elétrica.
} 
de $60 \%$ de picado e $40 \%$ de serragem, bagaço de cana e outros. A caldeira utilizada atende ainda aos requisitos de emissão dos gases na atmosfera, regulamentados por lei específica.

TABELA 5 - Descrição técnica da caldeira aquatubular usada na usina termoelétrica.

\begin{tabular}{lc}
\hline Potência de geração & $5 \mathrm{MW}$ \\
Geração de vapor & $\mathrm{t} / \mathrm{h}$ \\
Pressão do vapor & $42 \mathrm{bar}$ \\
Eficiência & $83 \%$ \\
Temperatura do vapor & $400^{\circ} \mathrm{C}$ \\
Turbina & Condensação Pura \\
Consumo de biomassa & $6,5 \mathrm{t} / \mathrm{h}$ \\
\hline
\end{tabular}

FONTE: Base Sólida Energia (2012).

Assim, como os resíduos gerados no período entre maio de 2007 e junho de 2012 correspondem ao total de $2.460 .469 .109,10 \mathrm{~kg}$ e tendo que a demanda de consumo de biomassa madeireira pela usina termoelétrica é de 6,5 toneladas por hora, destaca-se que o estoque existente sustentaria a usina por um período aproximado de 43,2 anos, isso sem levar em conta os resíduos gerados na continuidade da produção madeireira e aqueles gerados pela floresta, que, se calculados levando-se em conta o período mínimo de 189 anos para a exploração total, gerariam uma quantidade correspondente a 1.823.444.941,05 kg de resíduos, que seriam consumidos dentro de um período de 32 anos.

Deste modo, a produção de energia elétrica a partir da combustão da biomassa pode apresentar algumas vantagens e limitações destacadas por Cortez, Lora \& Gómez (2008, p. 580-581): como vantagens, a baixa emissão de gases de efeito estufa; a geração de empregos, minimizando o êxodo rural; e a diversificação da matriz energética, reduzindo os riscos de desabastecimento e de elevação dos custos da geração; e como limitações, os altos custos com o transporte da biomassa, que são determinantes para a viabilidade econômica dos projetos de geração elétrica; a abundância da biomassa usada; a produção sustentável dos pontos de vista ambiental, social e econômico; e a baixa eficiência de conversão da biomassa em eletricidade.

\subsubsection{Demonstração dos valores de implantação para a usina termoelétrica movida a biomassa madeireira}

Com o propósito de instalação de uma usina termoelétrica no município de Marcelândia-MT, para o consumo dos resíduos gerados por parte das indústrias do setor madeireiro, tem-se que tal alternativa apresenta importantes vantagens quando tratamos da redução dos impactos ambientais, da geração de postos de trabalho para a população, da redução dos custos relacionados à remoção dos resíduos de dentro do pátio das indústrias madeireiras e também da possibilidade de expansão da capacidade produtiva, pelo aumento da oferta energética na região.

Sendo assim, para se ter conhecimento da viabilidade da instalação da usina termoelétrica, torna-se necessária a demonstração dos valores que compõem o fluxo de caixa econômico do empreendimento, apresentando a linha de financiamento escolhida, os custos e receitas, dentre outros elementos importantes que o compõem.

Com relação ao financiamento para a instalação da usina termoelétrica, escolheu-se a linha de financiamento do FCO (Fundo Constitucional de Financiamento do Centro-Oeste) via Banco do Brasil, devido à baixa taxa de juros para este segmento, que é de 9,50\% a.a., com limite financiável de até $90 \%$ do total do investimento, pago em um prazo de 240 meses, contando neste prazo os 60 meses de carência, conforme a Tabela 6 (BB, 2008). 
Os dados mencionados na Tabela 6, referentes ao orçamento (item 1), descrevem a estrutura funcional da usina termoelétrica que será instalada no município de Marcelândia-MT. Dentre estes valores, tem-se que $90 \%$ do total do investimento será financiado pelo FCO, ou seja, um montante de R\$ 10.314.924,00.

São esboçadas a capacidade anual de geração de receitas do empreendimento termoelétrico e a somatória do faturamento dos itens que compõem a linha de produção, ou seja, a energia elétrica gerada, no nível de $100 \%$ de uso da capacidade efetiva instalada. O horário de funcionamento da usina será de 24 horas por dia, 30 dias mensais e 12 meses ao ano, parando apenas 2 dias/ano para a manutenção. Além disso, as receitas são consideradas constantes durante o período de financiamento (20 anos), sem acréscimo ou ajuste, levando-se em consideração o preço médio que chega a R\$ 122,12 por MWh, pago em leilões no mercado livre (CEMAT, 2012).

Para se chegar a esse preço médio, foi analisada a tabela de preços de energia térmica, disponibilizada pela instituição "Centrais Elétricas Mato-Grossenses" (CEMAT, 2012), no período de 2010 a 2024 ( $1^{\circ}$ Leilão de Energia Nova - 16/12/2005). A modalidade de compra é chamada de contrato leilão de energia CCEAR (Contrato de Comercialização de Energia Elétrica no Ambiente Regulado), realizado pela CEMAT.

Outro item a ser destacado são os insumos, no caso os resíduos madeireiros, que se encontram discriminados em dois grupos, a matéria-prima destinada à formação de estoque, que será obtida somente durante o ano zero, ou seja, durante o período de construção da usina, para o caso de haver imprevistos no decorrer do funcionamento da mesma; e a matéria-prima destinada à manutenção do estoque, que será adquirida durante os períodos de funcionamento da usina, ou seja, a partir do ano um.
TABELA6 - Resumo dos dados financeiros referentes à implantação da indústria termoelétrica.

\begin{tabular}{|c|c|}
\hline Discriminação & Valores Gerais (R\$) \\
\hline \multicolumn{2}{|l|}{ Orçamento } \\
\hline 1.2 Projeto & $149.000,00$ \\
\hline 1.3 Obras civis & $775.000,00$ \\
\hline 1.4 Máquinas e equipamentos & $9.453 .765,00$ \\
\hline 1.5 Equipamentos de informática & $10.000,00$ \\
\hline 1.6 Montagens/fretes & $331.994,00$ \\
\hline 1.7 Veículos & $185.000,00$ \\
\hline 1.8 Moveis e utensílios & $11.335,00$ \\
\hline 1.9 Treinamento & $20.000,00$ \\
\hline $\begin{array}{l}1.10 \text { Outros (pátio de biomassa e poço } \\
\text { artesiano) }\end{array}$ & $544.165,00$ \\
\hline \multicolumn{2}{|l|}{ Receitas } \\
\hline 2.1 Receita total anual (ceteris paribus) & $5.275 .584,00$ \\
\hline \multicolumn{2}{|l|}{ Insumos } \\
\hline 3.1 Matéria-prima para estoque & $533.520,00$ \\
\hline 3.1.1 Matéria-prima para manutenção & $617.760,00$ \\
\hline 3.2 Outras despesas/gastos & $177.180,00$ \\
\hline \multicolumn{2}{|l|}{ Mão de Obra Requerida } \\
\hline 4.1 Mão de obra fixa & $167.414,00$ \\
\hline 4.2 Mão de obra variável & $503.903,00$ \\
\hline \multicolumn{2}{|l|}{ Fluxo de Caixa } \\
\hline 5.1 Investimento inicial & $11.669 .008,00$ \\
\hline 5.1.1 Total financiável & $10.314 .924,00$ \\
\hline 5.1.2 Capital próprio & $1.165 .334,68$ \\
\hline 5.3 Juros sobre o financiamento & $11.200 .379,00$ \\
\hline 5.4 Juros pré-operacionais & $188.750,00$ \\
\hline 5.5 Total de usos & $21.694 .430,00$ \\
\hline
\end{tabular}

FONTE: Elaboração própria a partir dos dados do BB (2008).

Quanto à mão de obra requerida, esta se divide em dois grupos, fixa e variável, onde a maior parte dos funcionários apresenta uma carga horária de 8 horas/dia, com troca de turnos em alguns casos. Em relação aos encargos sociais e previdenciários que incidem sobre os funcionários, as taxas dos encargos são consideradas para realização do cálculo, além das despesas tributárias e contribuições.

Além disso, é evidenciado o fluxo de caixa do empreendimento termoelétrico de forma simples e resumida, trazendo os valores que compõem o in- 
vestimento inicial, o montante total dos juros pagos sobre o financiamento e os juros pré-operacionais, demonstrando assim a capacidade de pagamento do financiamento, que será realizado por meio das receitas obtidas pela venda da energia elétrica.

A avaliação de um projeto de viabilidade está relacionada ao mais amplo planejamento para a tomada de decisão de um investimento na área empresarial, ou seja, é necessário analisar os resultados preliminares, demonstrados na Tabela 7, para alocar eficientemente os recursos dentro da atividade produtiva, atendendo a demanda e oferecendo bens e serviços de qualidade.

TABELA7 - Resumo dos resultados econômico-financeiros da usina termoelétrica para o município de Marcelândia-MT.

\begin{tabular}{lc}
\hline Discriminação & Valores Gerais \\
\hline Lucro Contábil & $\mathrm{R} \$ 13.240 .654,00$ \\
T.I.R. & $9,81 \%$ \\
Payback & 6 anos \\
Margem Operacional & $42,52 \%$ \\
TMA & $10,00 \%$ \\
VPL & $\mathrm{R} \$ 1.509 .163,00$ \\
\hline
\end{tabular}

FONTE: Elaboração própria a partir dos dados do BB (2008).

Assim, percebe-se que a Taxa de Retorno (TIR) é próxima a Taxa Mínima de Atratividade (TMA) proposta no projeto e o Valor Presente Líquido (VPL) apresenta-se positivo, tornando assim o projeto aceitável. Quanto ao Payback, este consiste na quantificação do tempo necessário para que o valor investido seja recuperado por meio do montante gerado pelo empreendimento, que é analisado pelo fluxo de caixa. Deste modo, temos que o tempo de retorno do investimento total empregado no projeto será recuperado pelo investidor a partir do sexto ano.

Pode-se afirmar que a instalação da usina termoelétrica como alternativa para o consumo dos resíduos gerados pelas indústrias madeireiras do município de Marcelândia-MT é viável.
$\mathrm{Na}$ discussão evidenciada, quando destacadas as condições de aproveitamento do resíduo madeireiro como fonte energética a partir dos seus indicadores financeiros, abre-se um espaço para justificar tal empreendimento quando se ressalta o ganho econômico e ambiental que o município terá a partir de sua concepção.

Para tanto, faz-se necessário demonstrar os dados de consumo de energia elétrica ( $\mathrm{kWh}$ ), disponibilizados pela Rede Cemat (2012), segundo as classes residencial, industrial, comercial, rural e público em Marcelândia-MT no período de jan/2009 a jun/2012.

Desta forma, a Figura 4 apresenta o consumo de energia elétrica no período por classes para efeito de demonstração, onde percebeu-se que, do consumo total de 1.356.024 kWh em janeiro de 2012, para um total de 4.065 consumidores, as classes que mais consumiram foram as residenciais e as industriais.

Como a base industrial do município tem aproximadamente $90 \%$ voltada ao setor madeireiro, nota-se com os dados que o consumo de energia do setor industrial diminui pela metade no mês de janeiro, porém apresentando quedas a partir do mês de novembro, em função das chuvas, que dificultam o processo de extração da madeira e sua industrialização.

Outro ponto a ser ressaltado é a redução do número de indústrias ao longo do período, pois em janeiro de 2009 contava-se com 96 indústrias, com uma redução em junho de 2010 para 72 empresas, em função do incêndio que aconteceu gerando um impacto negativo no setor, e em junho de 2012 com o setor novamente em expansão, apresentando um total de 83 indústrias.

Portanto, por meio dos dados do consumo médio de energia elétrica de Marcelândia-MT (1.382.268 kWh) e da geração de energia por parte da usina termoelétrica, que será de $5 \mathrm{MW}$ de 


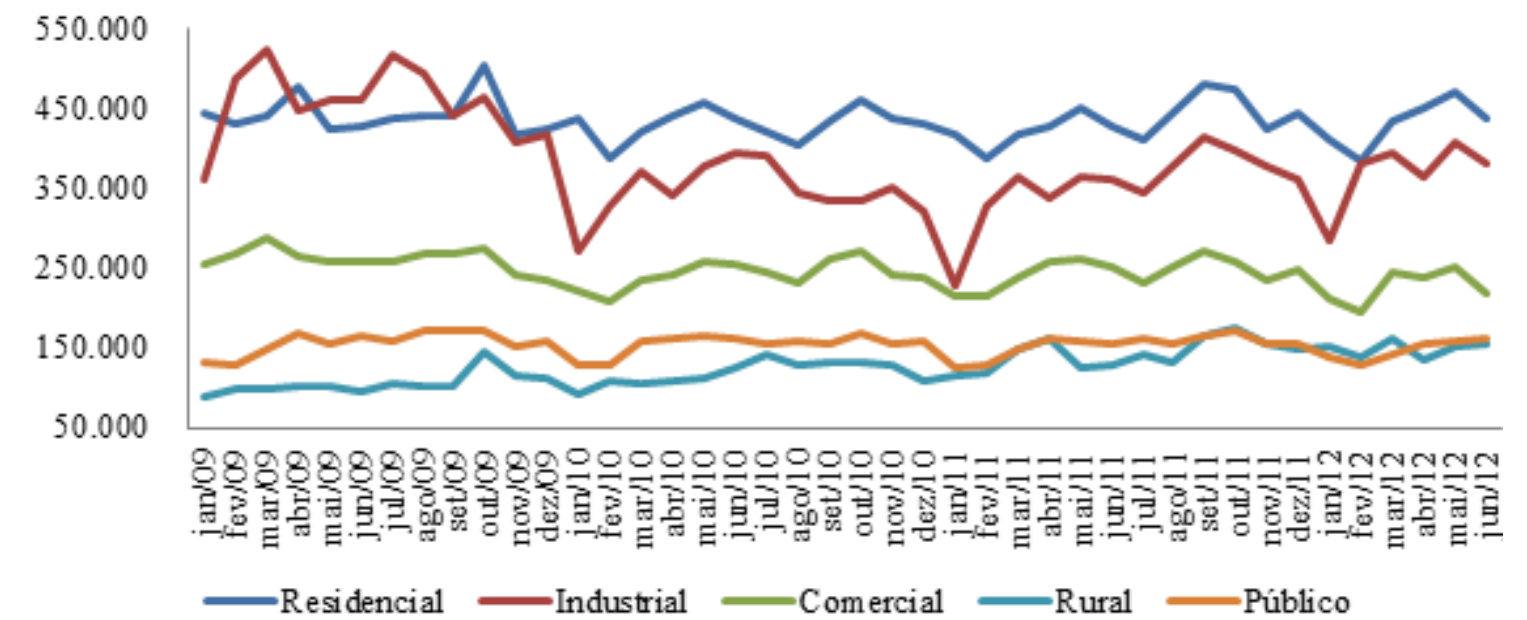

FIGURA 4 - Consumo Médio de Energia Elétrica (kWh) por Classe no município de Marcelândia-MT.

FONTE: CEMAT (2012).

potência, enfatiza-se que a demanda existente será suprida pela oferta excedente gerada pela indústria, podendo atender as classes consumidoras localizadas no município e ser vendido o excedente para o consumo em outros municípios e regiões.

\section{Considerações finais}

Verificou-se que, devido ao município de Marcelândia-MT ter sua economia baseada no setor madeireiro, existem grandes estoques de resíduos madeireiros que não possuem destinação definida. Os resíduos gerados e classificados como de origem e de destino, entre maio de 2007 e junho de 2012, somam $8.914 .743,13 \mathrm{~m}^{3}$, o que corresponde a $2.460 .469 .109,10 \mathrm{~kg}$ de pó de serra.

Em Marcelândia-MT, existem 18 manejos florestais, correspondentes a $15.935 .080,97 \mathrm{~m}^{3}, \mathrm{com}$ potencial de serem explorados de forma manejada por, no mínimo, 189 anos, quando se atingiria o esgotamento destes, considerando uma exploração média anual de $84.312,59 \mathrm{~m}^{3}$. Neste cenário, con- siderando o aproveitamento médio do volume total de tora $(58,54 \%)$, ter-se-ia uma geração total de $6.606 .684,57 \mathrm{~m}^{3}$ de resíduos a serem aproveitados economicamente.

$\mathrm{O}$ aproveitamento dos resíduos madeireiros gerados em Marcelândia-MT na geração de energia por meio de usina termoelétrica apresenta-se com potencial de transformar uma externalidade negativa (disposição inadequada dos resíduos) em uma externalidade positiva (geração de energia), tendo em vista que o estoque de resíduos madeireiros existente é suficiente para sustentar uma usina por um período aproximado de 43,2 anos, isso sem levar em consideração os resíduos gerados na continuidade da produção madeireira, com potencial de extração por mais 189 anos, além daqueles gerados por floresta, que, se calculados, gerariam uma quantidade de resíduos equivalente à que seria demandada para operar uma usina por 32 anos.

Esta proposta de investimento demonstra-se viável, possuindo taxa interna de retorno (TIR) próxima à taxa mínima de atratividade esperada 
(TMA), valor presente líquido (VPL) positivo e retorno do investimento a partir do sexto ano, com lucro contábil de R\$ 13.240.654,00.

Considerando o cenário proposto, a demanda de energia existente no município (1.382.268kWh) poderia ser suprida por uma usina termoelétrica abastecida pelos resíduos madeireiros gerados localmente. Assim, todas as classes consumidoras do município poderiam ser atendidas e o excedente de energia poderia ser comercializado.

\section{Referências}

ABRAF - Associação Brasileira de Produtores de Florestas Plantadas. Anuário estatístico da ABRAF 2011, ano base 2010. Brasília: ABRAF, 2011. p. 130.

Amazonas, M. de C. Economia ambiental neoclássica e desenvolvimento sustentável. Relatório parcial da pesquisa CEBRAP-IBAMA. 2012. Disponível em: <https://xa.yimg. com/kq/groups/24872712/1396840763/name/econo-amb. pdf $>$. Acesso em: jul. 2012.

Andrade, D. C. Economia e meio ambiente: aspectos teóricos e metodológicos nas visões neoclássica e da economia ecológica. Leituras de Economia Política, Campinas, 14, 1-31, 2008.

ANEEL - Agência Nacional de Energia Elétrica. Banco de Informações de Geração da Agência Nacional de Energia Elétrica-BIG. 2012. Disponível em: <http://www2.aneel. gov.br/aplicacoes/capacidadebrasil/capacidadebrasil.cfm>. Acesso em: nov. 2012.

BB - Banco do Brasil. Planilha do Fundo Constitucional de Financiamento do Centro-Oeste. 2008. Disponível em: $<$ http://www.bb.com.br/portalbb/page100,107,2837,9,1,1,2. bb? codigoNoticia $=2243 \&$ codigoMenu $=133 \&$ codigoRet $=1$ 965\&bread=2_3>. Acesso em: fev. 2015.

Base Sólida Energia. Pinhais-PR, 2012. Disponível em: $<$ http://www.basesolidaenergia.com.br/>. Acesso em: out. 2012.

Benecke - Benecke Irmãos e Cia Ltda. Timbó-SC, 2012. Disponível em: <http://www.benecke.com.br/>. Acesso em: out. 2012.

Bio Versátil. Serviços Florestais e Assessoria Empresarial LTDA ME. Sinop-MT, 2012.

Brasil. Empresa de Pesquisa Energética (EPE). Balanço Energético Nacional 2015: Ano Base 2014 - Relatório Síntese. Rio de Janeiro: EPE, 2015.
CEMAT - Centrais Elétricas Mato-Grossenses S.A. 2012. Disponível em: $<$ http://www.cemat.com.br/>. Acesso em: jul. 2012.

CIFLORESTAS - Centro de Inteligência em Florestas. Marcelândia: prioridade também é reconstruir madeireiras. 2010. Disponível em: <http://www.ciflorestas.com.br/ conteudo.php?id=3515> . Acesso em: fev. 2015.

Cortez, L. A. B.; Lora, E. E. S.; Gómez, E. O. Biomassa para energia. Campinas, SP: Unicamp, 2008.

Farra, F. C. P. D. Análise econômico-energética de utilização de resíduo industrial florestal para geração de energia térmica: um estudo de caso. 2004. Botucatu, Dissertação (Mestrado em Agronomia) - UNESP “Julio de Mesquita Filho", 2004.

Fontenelle, M. Tecnologia em Manutenção Industrial: máquinas térmicas, geradores de vapor de água. Chapecó-SC: SENAI-CTAL, 2012. Disponível em: <http://www. slideshare.net/RhanaAmanda/56984941-apostilacaldeiras>. Acesso em: fev. 2015.

Gomes, J. I.; Sampaio, S. S. Comunicado Técnico 102. Aproveitamento de resíduos de madeira em três empresas madeireiras do Estado do Pará. Bélem-PA: EMBRAPA, 2004. Disponível em: <http://www.infoteca.cnptia.embrapa.br/bitstream/doc/395422/1/com.tec.102.pdf>. Acesso em: fev. 2015.

IBGE - Instituto Brasileiro de Geografia e Estatística. Produção da extração vegetal e da silvicultura. Rio de Janeiro: IBGE, 2010. Disponível em: <http://www.ibge. gov.br/home/estatistica/economia/pevs/2010/comentario. pdf>. Acesso em: fev. 2015.

IBGE - Instituto Brasileiro de Geografia e Estatística. Banco de dados SIDRA. Produção da extração vegetal 1990-2010. 2012. Disponível em: <http://www.sidra.ibge. 
gov.br/bda/tabela/listabl.asp?c $=289 \& \mathrm{z}=\mathrm{t} \& \mathrm{o}=18>$. Acesso em: ago. 2012.

IMEA - Instituto Mato-grossense de Economia Agropecuária. Apresentação MT. Dados de apresentação. 2012.

Juvenal, T. L.; Mattos, R. L. G. O setor florestal no Brasil e a importância do reflorestamento. BNDES Setorial, n. 16, 2002.

May, P. H. (Org.). Economia do meio ambiente: teoria e prática. 2. ed. Rio de Janeiro: Elsevier, 2010.

Oliveira, C. A Saga dos guardiões da floresta: uma viagem emocionante à história do setor de base florestal de Mato Grosso. Sinop: Sindusmad/Print, 2011.

PNUD - Programa das Nações Unidas para o Desenvolvimento. Diagnóstico das condições de saneamento nas sedes dos municípios do Estado de Mato Grosso inseridos na bacia hidrográfica do rio Xingu. Relatório Final. Goiânia, 2005.

Portal Mato Grosso. Mapa do município de Marcelândia. 2012. Disponível em: <http://www.mteseusmunicipios. com. br/NG/conteudo.php?sid=170\&cid=2503>. Acesso em: fev. 2015.

Prefeitura Municipal de Marcelândia. Economia. 2012. Disponível em: <http://www.marcelandia.mt.gov.br/Economia/>. Acesso em: fev. 2015.

Preto, E. V.; Mortoza, G. L. Geração de energia elétrica utilizando biomassa. Brasília. 2010. Brasília, Monografia (Graduação em Engenharia Elétrica) - UnB, 2010.

REMADE - Revista da Madeira. Madeira é a maior fonte de energia renovável na Europa. N. 136, ano 24. Circulação dirigida, 2013. Disponível em: <http://pt.calameo.com/ $\mathrm{read} / 00229864828 \mathrm{a} 29407647 \mathrm{e}>$. Acesso em: jan. 2016.
Rosalino, T.; Dalfovo, W. C. T. A produção de resíduos industriais madeireiros a partir da atividade das indústrias madeireiras no município de Marcelândia-MT no período de 2007 a 2010. Congresso de Iniciação Científica, 7. ed., 2011. Cáceres: Pró-Reitoria de Pesquisa e Pós-Graduação, 2011.

Santos, M. E. dos. Avaliação do gerenciamento de resíduos sólidos em indústrias de extração e transformação de madeiras localizadas no Amazônia mato-grossense. 2011. Ribeirão Preto, Dissertação (Mestrado em Ciências) - USP, 2011.

SEMA - Secretaria de Estado do Meio Ambiente. Portaria $n^{\circ}$ 096, de 18 de junho de 2010. Disponível em: $<$ http://www.sema.mt.gov.br/index.php?option=com docman \&task $=$ doc download $\&$ gid $=566 \&$ Itemid $=173>$. Acesso em: fev. 2015.

SEMA - Secretaria de Estado do Meio Ambiente. SISFLORA Auditoria. 2012. Disponível em: $<$ https://monitoramento.sema.mt.gov.br/auditoria/>. Acesso em: fev. 2015.

Teixeira, M. G.; César, S. F. Produção de compósito com resíduo de madeira no contexto da ecologia industrial. 10. ed. São Paulo: EBRAMEM - Encontro Brasileiro em Madeiras e em Estruturas de Madeira, 2006.

Teixeira, T. V. R. Uso da madeira e derivados para energia no Estado do Paraná. 2009. Curitiba, Trabalho de Conclusão do Curso (Graduação em Engenharia Industrial Madeireira) - UFPR, 2009.

Ventura, M. H. O impacto econômico da política de controle ambiental no polo madeireiro de Sinop no periodo de 2001 a 2010. Sinop-MT: UNEMAT, 2012.

Vital, M. H. F. Florestas independentes no Brasil. BNDES Setorial, n. 29, p. 77-130, 2009. 